\author{
(1) Hamza Yıldız, \\ (1) Erdal Pan*, \\ (1) Abdullah Bolu*
}

\section{Folie á Famille: Olgu Sunumu Folie á Famille: Case Report}

\title{
Öz
}

Delüzyonel parazitoz (DP) çok nadir görülen kronik bir psikiyatrik bozukluktur. Hastalarda herhangi bir klinik bulgu olmamasına rağmen parazitlerle enfekte olduklarına dair yanlış ve sabit bir inanış vardır. Folie á famille aile üyelerinin tamamında paylaşımış psikotik bozukluk olmasıdır. Burada DP olgu ve paylaşılmış psikotik bozukluğu olan anne, baba, kız çocuğu, anneanne ve dededen oluşan toplam 5 kişilik bir aile sunulmaktadır.

Anahtar kelimeler: Delüzyonel parazitoz, folie á famille, paylaşımış psikotik bozukluk

\section{Abstract}

Delusional parasitosis (DP) is a very rare chronic psychiatric disorder. Although there are no any clinical symptoms in patients, there is a false and fixed belief that they are infected with parasites. Folie a famille is characterized as a shared psychotic disorder within all the family members. Herein, we present a family total of five people including mother, father, daughter, grandmother and grandfather who diagnosed with DP and have shared psychotic disorder.

Keywords: Delusional parasitosis, folie á famille, shared psychotic disorder

\section{Giriş}

Delüzyonel parazitoz (DP); tıbbi bir kanıt olmamasına rağmen kişinin parazit ya da yaşayan küçük yaratıklar tarafından enfekte olduğu yanlış ve ısrarlı inancı ile seyreden sanrısal bir bozukluktur. DP tanısı bir ailedeiki kişiye konulduğunda 'folie à deux', üç kişiye konulduğunda'folie à trois'olarak adlandırılır. Fakat tüm aileye DP tanısı konulmuş ise'folie à famille' olarak adlandırılmaktadır $(1,2)$. Bu makalede delüzyonel parazitozlu bir aile (folie á famille) sunulmaktadır.

*Eskişehir Asker Hastanesi, Psikiyatri Kliniği, Eskişehir, Türkiye

Yazışma Adresi/ Correspondence:

Hamza Yıldız, Eskişehir Asker Hastanesi, Deri ve Zührevi Hastalliklar Kliniği, Eskişehir, Türkiye E-posta: hamzayildiz@gmail.com ORCID-ID:

orcid.org/0000-0001-5817-8571 Geliş Tarihi/Submitted: 02.07.2014 Kabul Tarihi/Accepted: 12.10.2014

๑Telif Hakkı 2019 Türk Dermatoloji Derneği Türk Dermatoloji Dergisi, Galenos Yayınevi tarafından basılmıştır.

\section{Olgu Sunumu}

Beş kişilik aile tedavi edilemeyen bitlenme şikâyeti ile polikliniğimize başvurdu. Hastaların şikâyetleri 4 yaşındaki kız çocuklarının üç buçuk ay önce kreşte saçının bitlendiği söylendikten sonra başlamış. $\mathrm{K}$ ız çocuğuna tedavi uygulanmış fakat bu sırada annede (32), baba (34), anneanne (48) ve dede (56) de benzer kaşıntı şikâyetleri meydana gelmiş. Hastalar yaklaşık olarak 60 kez bit tedavisi ve birkaç kez de veterinerden aldıkları pestisitleri kullandıklarını, yaygın kaşıntı ve yanma şikâyetlerinin devam ettiğini belirttiler.
Tüm aile bireyleri 3-4 kez saçlarını kestirmiş. Anne ve anneanne tüm vücut kıllarını kesmiş. Hastalar bu ile başka bir ilden gelmişler. Yaşadıkları evin tüm eşyalarını çöpe atıp yenisini aldıkları halde ama bitlenmelerinin devam ettiğini ifade ediyorlar. Giydikleri tüm kıyafetleri atmışlar veya yakmışlar, ikinci bir kez giymemişler. Evlerini ilaçlattıklarını ve evlerini terk edip bitlerden kurtulmak için ilimize gelmişler. Anneanne ve dedenin evininde bitlendiğini için bu evide terk etmişler. Şuan bir misafirhanede kaldıklarını ifade eden hastaların tamamı dermatoloji kliniğimize yatırıldı.

Hastaların dermatolojik muayenesinde parazite rastlanmadı. Hastaların saçlı derisinde, boyunda, gövde ve sırtta irritan kontakt dermatit plakları izlendi (Resim 1). Hastalar kliniğimize yatırıldı. Hasta onam formları alındı. Topikal nemlendirici ve oral antihistaminik başlandı. Hastalar yakaladıkları bitleri kutulara koyup incelenmek üzere bize teslim ettiler. Dermatoskopik incelemede verilen materyallerin ip parçacıkları ve keratinize doku parçaları olduğu saptandı (Resim 2). Psikiyatri konsültasyonu alındı. Minnesota 
Çok Yönlü Kişilik Testi Envanteri hastaya uygulandı. Anneye klinik ve laboratuvar bulguları eşliğinde "delüzyonel parazitoz" tanısı kondu. Diğer 4 hastanın bu hastadan etkilenen olgular (paylaşılmış psikotik bozukluk) olduğu değerlendirildi. Anneye oral $5 \mathrm{mg} / \mathrm{gün}$ olanzapin tedavisi başlandı. Diğer aile bireyleri verdiğimiz topikal tedaviden (vazelin pür) fayda gördüler. Şikayetleri tama yakın geriledi ve taburcu edildiler. Fakat maalesef anne taburcu olduktan sonra psikiyatri polikliniği takiplerine gelmedi.

\section{Tartışma}

Delüzyonel parazitoz nadir görülen bir psikiyatrik bozukluktur. Herhangi bir enfeksiyon olmamasına rağmen hastalarda enfekte olduklarına dair bir inanış vardır. Bu hastalar psikiyatristlerden ziyade dermatolog, dahiliye uzmanı, aile hekimi gibi diğer hekimlere başvururlar. Bunun sebebi ise bu hastalar bedensel bir hastalığa yakalandıklarını ve bu hastalığın psikiyatrik tedavi ile tedavi edilemeyeceği düşüncesinin hakim olmasıdır (1). DP

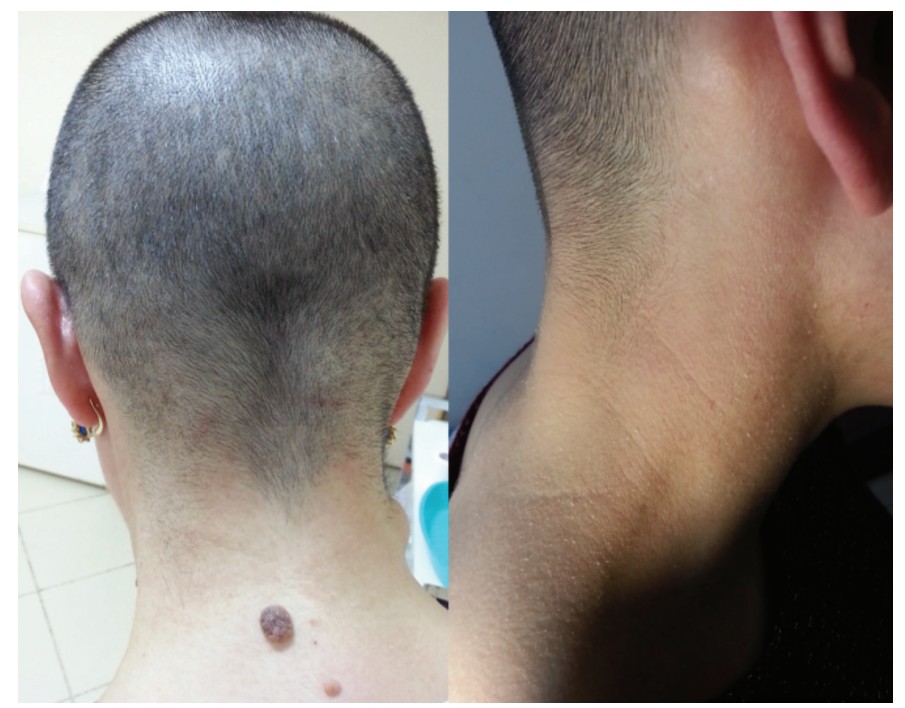

Resim 1. Hastanın saçlı deri ve ensesinde irritan kontakt dermatit

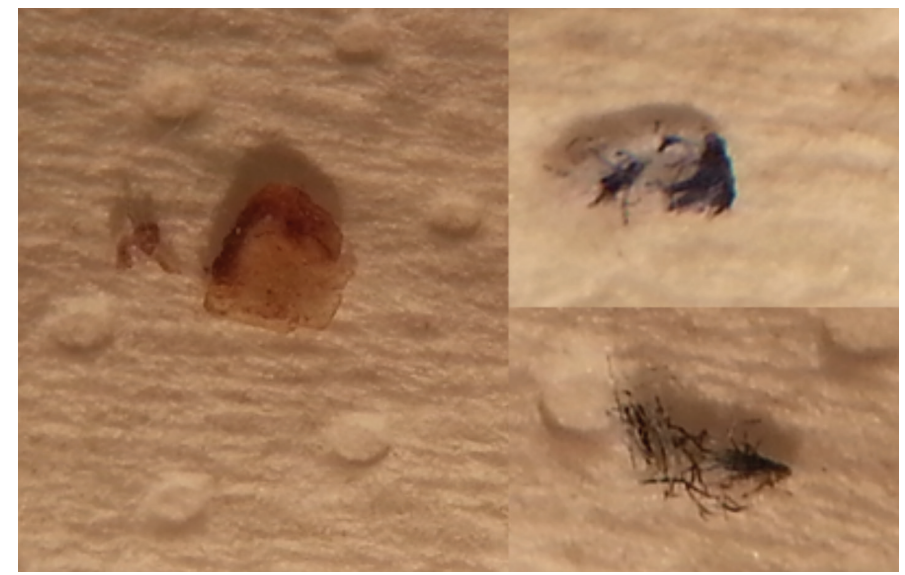

Resim 2. Dermatoskopik incelemede deri ve iplik parçaları başka psikiyatrik hastalıklar ile birlikte görülebileceği gibi tek başına da görülebilir. Hastalarımızın tamamı psikiyatri uzmanı tarafından değerlendirildi. Hastalarda eşlik eden psikopatoloji saptanmadı. Eşlik edebilecek bedensel hastalıklar için tam kan sayımı, rutin biyokimya, prolaktin, Salmonella tüp aglütinasyon testi, Brucella aglütinasyon testi, TSH, T3, T4, HBs Ag, anti-HIV, VDRL, vitamin B12, folik asit, ferritin tetkikleri yapıldı. Laboratuvar sonuçları normal sınırlarda idi.

DP'nin klinik görünümü değişik şekillerde olabilir. Sık görülen belirtiler şunlardır; kaşıntı, batıcı tarzda ağrı, yanma, kibrit kutusu belirtisi (matchbox sign). Vücut kıllarının ve saçların kesilmesi/traşlanması hatta vücuda çeşitli pestisitlerin kullanılması gibi kendine zarar verici davranışlar gözlenebilir. Çok nadir olarak işitsel varsanılara da rastlanabilir $(1,2)$. Hastalarımız saçlarını ve vücut kıllarını 2-3 kez tıraş ettiğini (Resim 1) ve $3 \mathrm{kez}$ vücutlarına pestisitler uyguladıklarını belirtti. Hastalarımız kliniğe yattıkları yedi günlük dönemde, çeşitli kutularda ve peçete içinde topladıkları parazitleri bize verdiler. Verilen materyaller dermatoskopik olarak incelendi. Dermatoskopik incelemede deri ve iplik parçaları gözlendi. Kibrit kutusu belirtisi (matchbox sign) pozitif olarak değerlendirildi. Bazı olgularda kronik kaşımaya bağlı likenifikasyon, sürekli kullanılan dermatolojik ilaçlarla irritan kontakt dermatit geliştiği görülebilir (3). Olgumuzda saçlı deri, boyun, gövde ve bacaklarda yer yer irritan kontakt dermatit izlenmekteydi. Avrupa'da ve dünyada DP sıklığı ile ilgili kesin veriler bulunmamaktadır. Genellikle DP hastaları tek tek olgu sunumları ya da küçük gruplar halinde bildirilmektedir. DP az rastlanan bir psikiyatrik hastalıktır. DP'li olgularda "paylaşılmış psikotik bozukluğun" (PPB) eşlik etme oranı $\% 5-15$ civarındadır $(4,5)$. PPB genellikle aile üyeleri arasında görülmektedir.

Hastalığı taşıyan birincil aile üyeleri de bu sanrıya katılmaktadır $(2,6)$. Biz de hastalarımızın "folie à famille" tanısı ile uyumlu olduğunu değerlendirdik. Annenin birincil olgu olduğu ve diğer aile bireylerinin etkilenen olgular olduğu değerlendirildi. Kadınlar erkeklerden daha fazla etkilenmektedir. Bizim birincil olgumuz 32 yaşında kadın hastaydı.

DP psikiyatrik bir hastalık olmasına rağmen hastalar genellikle dermatoloji polikliniğine başvurmaktadırlar. DP tanısının konmasında dermatologların rolü büyüktür. DP tanısının klinisyenin aklına gelmesi ve belirtilerin dikkatli bir şekilde araştırılması durumunda konulabileceğine dikkat edilmedir. Bu olgu sunumu nadir olarak görülen ve az bilinen delüzyonel parazitozun akılda tutulması gerektiğinin vurgulanması amacıyla sunulmaya değer bulunuldu.

\section{Etik}

Hasta Onayı: Hasta onam formları alınmıştır.

Hakem Değerlendirmesi: Editörler kurulu dışında olan kişiler tarafından değerlendirilmiştir. 


\section{Yazarlık Katkıları}

Cerrahi ve Medikal Uygulama: H.Y., E.P., A.B., Konsept: H.Y., Dizayn: H.Y., Veri Toplama veya İşleme: H.Y., Analiz veya Yorumlama: H.Y., Literatür Arama: H.Y., E.P., A.B., Yazan: H.Y.

Çıkar Çatışması: Yazarlar tarafından çıkar çatışması bildirilmemiştir.

Finansal Destek: Yazarlar tarafından finansal destek almadıkları bildirilmiştir.

\section{Kaynaklar}

1. Mercan S, Öğütcan Ö, Altunay İK, et al. Folie à famille ve delüzyonel parazitoz: olgu sunumu ve literatürün gözden geçirilmesi. Klinik psikofarmokoloji Bülteni 2005;15:71-8.
2. Almila E, Ersoy B, Gulpek D, et al. Folie a famille: case report. Anatolian Journal of Psychiatry 2008;9:261-4.

3. Altunay Ki, Köşlü A. Psikojenik pruritus. Türk Dermatoloji Dergisi 2008;2:116-20.

4. Daniel E, Srinisan TN. Folie a Famille: delusional parasitosis affecting all the memebers of a family. Indian J Dermatol Venereol Leprol 2004;70:296-7.

5. Uzun SK, Erturan İ. Psikodermatoloji. Türk Dermatoloji Dergisi 2014;1:1-6.

6. Foster AA, Hylwa SA, Bury JE, et al. DElusional infestation: clinical presentation in 147 patients seen at Mayo Clinic. J Am Acad Dermatol 2012;67:673. 